\title{
Geo-accumulation and Health risk of trace metals in road dust of the residential areas close to Industrial sites of Delhi. \\ ZAINAB SIDDIQUI ${ }^{1}$ AND P.S.KHILLARE ${ }^{2}$
}

${ }^{1}$ Zainab Siddiqui is with the School of Environmental Sciences, Jawaharlal Nehru University, New Delhi 110067, India, (e-mail: zainab35_ses@jnu.ac.in).

${ }^{2}$ P.S.Khillare is with the School of Environmental Sciences, Jawaharlal Nehru University, New Delhi 110067, India, (phone: 01126704325; e-mail: psk@mail.jnu.ac.in).

\begin{abstract}
This study investigates the trace metal content of the road dust and its health impacts on the population of Delhi. Delhi is a rapidly urbanising city, where vehicular fleet is very higher. With increasing number of industries, motor vehicles and population, the pollution load of the city is also growing. The city holds many complex setups of its major and minor industries surrounding the residential areas. There is no clear boundary between industrial and residential areas. People residing in and around the industries in Delhi are assumed to have greater exposure to industrial pollution. In the present study, road dust samples were collected from residential areas (which are close to major industrial area of the city) in the winter season of the year 2018. Before analysis, all samples were processed, homogenised and subsequently subjected to acid assisted Microwave digestion. The total trace metal analysis was carried out by Atomic Absorption Spectrophotometer. The result indicated that the distribution patterns of the trace metals in road dust were in the decreasing order as $\mathrm{Fe}>\mathrm{Mn}>\mathrm{Zn}>\mathrm{Cr}>\mathrm{Pb}>\mathrm{Cu}>\mathrm{Ni}>\mathrm{Co}$. Pollution index like $\mathrm{Geo}$ accumulation index $\left(\mathrm{I}_{\mathrm{geo}}\right)$ values were calculated to assess the degree of contamination of each metal. A high Igeo value was observed for $\mathrm{Cr}$ (3.2) followed by $\mathrm{Pb}(2.8)$ and $\mathrm{Cu}(2.7)$. The high geo accumulation suggests anthropogenic enrichment of the metals over a prolonged period. Human Health risk assessment was also carried out to infer the probability of carcinogenic and non-carcinogenic risk of the trace metal therein. The carcinogenicity for metals known as probable carcinogens (WHO) was also calculated by all possible exposure pathways; ingestion, inhalation and dermal. The value of Hazard index (HI) showed that all the studied metals are in safe limits, but $\mathrm{Mn}(\mathrm{HI}>1)$ can pose the non-carcinogenic risk to the exposed children. The carcinogenic risk from $\mathrm{Cr}$ was higher for the ingestion pathway. Metals like $\mathrm{Ni}, \mathrm{Cr}$ and $\mathrm{Pb}$ showed carcinogenicity with this observed concentration. Health implications in road dust by $\mathrm{Ni}, \mathrm{Cr}$ and $\mathrm{Pb}$ in studied residential areas strengthen the fact that urban population are prone to high carcinogenic risk.
\end{abstract}

Keywords- Health risk assessment; road dust; Geo-accumulation; Carcinogenic risk; Delhi 